\title{
Prostate Cancer Treatment and Related Psychosexual Sequelae
}

The majority of men after radical prostatectomy, never regain preoperative levels of erectile function without further treatment [1]. This is due to the removal of prostate either damaging/removing nerves to the penis as part of prostate removal. Erectile function is compounded by an ageing physical function, and as a result worsening sexual function for men. A recent focus group study conducted with both men with psychosexual concerns found that sexual problems were associated with a variety of common physical adverse effects such as cardiovascular comorbidity [2]. Post radical therapy, there are side effects including reduced penile length, loss of desire, and loss of orgasmic satisfaction in the patient [1] all of which contribute to erectile dysfunction requiring psychosexual care.

\section{References}

1. Bober SL, Sanchez Varela V. Sexuality in adult cancer survivors: challenges and intervention. J Clin Oncol. 2012;30:3712-9.

2. Flynn KE, Jeffery DD, Keefe FJ, Porter LS, Shelby RA, Fawzy MR, Gosselin TK, Reeve BB, Weinfurt KP. Sexual functioning along the cancer continuum: focus group results from the Patient-Reported Outcomes Measurement Information System (PROMIS). Psychooncology. 2011;20:378-86. 